\title{
Studies of Environmental Hazards and Groundwater Potential Zones of Arkavathi Catchment of Greater Bangalore Area, Karnataka, South India
}

\author{
Venkatesha G. ${ }^{1 *}$, Shivendra B.T. ${ }^{1}$, Ramaraju H.K. ${ }^{1}$, Chandrakanth G. ${ }^{2}$ \\ ${ }^{1}$ Dayananda Sagar College of Engineering, Bengaluru, India \\ ${ }^{2}$ Kuvempu University, India \\ *venkateshageo@gmail.com
}

\begin{abstract}
Water, air and soil are three important natural resources in which water is the most important natural resource which is polluted qualitatively. Remote sensing and geographical information system data is a powerful and effective tool for identifying pollution and potential zones of groundwater. Peenya industrial wastewater and domestic sewage flows in Arkavathi river catchment in the Greater Bangalore area due to which water gets polluted and enters into the groundwater aquifers through geological structures. The main objective of the study is to know the role of geological structures as avenues for ground water contamination and the mechanisms of aquifer pollutions and identification of the potential zones for ground water in the Arkavathi river catchment using remote sensing, geographical information system and geophysical techniques. Monsoon, pre-monsoon and post monsoon water samples were collected and analysed in the laboratory as per the Bureau of Indian standards parameters (BIS 10500-1991). Results indicated that many water quality parameters were above the permissible limit. The thematic maps such as geology, geomorphology, lineaments, slope, soil maps and land use/land cover etc. were prepared using the satellite imagery (IRS P6 LISS IV MX) and Survey of India Topo sheets. Electrical resistivity survey was carried out at 11 locations in the Arkavathi river catchment to find out the thickness of the underground layers and to know the depth range of the fractured zone, depth to basement and lineaments which plays a significant role in ground water pollution and potentiality particularly in hard rocks. The potential zones were identified mainly using the thematic maps, secondary or collateral data and correlating with vertical electrical soundings (VES) data. The study has revealed that the geological structures are the main carrier of the pollutant particles. The study also shows that Arkavathi river catchment is more polluted due to higher concentrations of lineaments, weathered zone and shear zones identified by VES, remote sensing and geographical information system data which forms the avenues for circulation and infiltration of pollutants into the aquifer. Good ground water potential zones are confined along lineaments, valley, valley fill and water bodies (19.54 \% of the total study area) and Pediplain shallow weathered, pediplain eroded, plains and mounds form a moderate potential zone ( $74.51 \%$ of the total study area). Other geomorphic units like pediments form a moderate to poor $(3.72 \%$ of the total study area), pediment inselberg complex form a poor prospect zone (1.71\% of the total study area) and poor to nil ( $0.51 \%$ of the total study area) occupies a small portion of study area composed mainly of Residual hills.
\end{abstract}

Keywords: Water quality, Geological structures, Geomorphology, Satellite imagery, Groundwater Potential Zone.

Proceedings of the $22^{\text {nd }}$ International Forestry and Environment Symposium 2017 of the Department of Forestry and Environmental Science, University of Sri Jayewardenepura, Sri Lanka 